\title{
KESESUAIAN CT SCAN LEHER DENGAN HASIL BIOPSI ASPIRASI JARUM HALUS DALAM MENGIDENTIFIKASI KEGANASAN LIMFADENOPATI LEHER
}

\section{THE RELATIONSHIP OF NECK CT SCAN AND THE RESULT OF FINE NEEDLE ASPIRATION BIOPSY IN DETERMINING MALIGNANTCY OF COLLI LYMPHADENOPATHIES}

\author{
Nur Intan Kasmin Ginano*, Mirna Muis, Bachtiar Murtala \\ Departemen Radiologi, Fakultas Kedokteran, Universitas Hasanuddin \\ Jalan Perintis Kemerdekaan Km.10, Makassar
}

\begin{abstract}
ABSTRAK
Limfadenopati dapat disebabkan oleh berbagai kondisi mulai dari keganasan, infeksi, autoimun, dan iatrogenik. Limfadenopati pada usia anak dan dewasa yang ukurannya tidak bertambah besar dalam kurun waktu kurang dari dua minggu atau lebih dari 12 bulan tidak bersifat neoplastik. Penelitian ini bertujuan mengetahui kesesuaian gambaran CT Scan leher dengan hasil biopsi aspirasi jarum halus (BAJAH) untuk membedakan limfadenopati leher yang jinak dan ganas. Penelitian ini dilaksanakan di Departemen Radiologi RS. Dr. Wahidin Sudirohusodo dan RS Universitas Hasanuddin Makassar mulai bulan Desember 2017 sampai Mei 2018. Sampel sebanyak 61 orang dengan rentang usia 4 - 82 tahun. Metode yang digunakan adalah observasional analitik dengan pendekatan cross sectional. Hasil penelitian menunjukkan gambaran keganasan limfadenopati leher pada CT Scan yang sesuai dengan BAJAH yaitu penyebaran ekstrakapsular, nekrosis sentral, bentuk bulat/lobulated dan margin irregular, sedangkan kalsifikasi dan ukuran tidak sesuai. Gambaran CT Scan limfadenopati leher yang jinak sesuai dengan hasil BAJAH yaitu tidak ada penyebaran ekstrakapsular, tidak ada nekrosis sentral, bentuk oval dan margin regular, sedangkan kalsifikasi dan ukuran tidak sesuai.
\end{abstract}

Kata kunci : BAJAH, CT Scan leher, limfadenopati leher

\begin{abstract}
Lymphadenopathy can be caused by various conditions that were malignancy, infection, autoimmunity, and iatrogenic. In adults and children, lymphadenopathy whose duration is less than two weeks or more than 12 months but its size does not increase, that is not a neoplastic. The study aims to determine the relationship between CT Scan of neck image and the result of fine needle aspiration biopsy (FNAB) in distinguishing benign and malignant cervical
\end{abstract}


lymphadenopathies. The research was conducted in Radiology Department of Dr. Wahidin Sudirohusodo and Universitas Hasanuddin Hospital Makassar from December to May 2018. The sample were 61 people aged form $4-82$ years old. The observational analytic with cross sectional analytic were used in this study. The result revealed that image of malignant lymphadenopathies in CT Scan of neck were significantly related with FNAB results; extracapsular spread; central necrosis, lobulated or rounded forms with irregular margin, while calcification and size were not related. The image of benign lymphadenopathies in CT Scan of neck was related with FNAB results; no extracapsular spread, no central necrosis, oval formed with regular margin, while calcification and size were not related.

Keywords : FNAB, neck CT Scan, neck lymphadenopathy

\section{Penulis korespondensi:}

Nur Intan Kasmin Ginano

Departemen Radiologi

Fakultas Kedokteran Universitas Hasanuddin,

Jalan Perintis Kemerdekaan, Makassar, Sulawesi Selatan, 90245

Email : nurintanginano@gmail.com

\section{PENDAHULUAN}

Limfadenopati adalah suatu kondisi dimana kelenjar limfa mengalami gangguan baik dari segi ukuran, bentuk, konsistensi, maupun jumlah (Darne \& Radja, 2016). Abnormalitas kelenjar limfa berdasarkan ukurannya dipengaruhi oleh usia dan lokasi. Pada umumnya kelenjar limfa dikatakan abnormal jika ukurannya lebih dari $1 \mathrm{~cm}$. Kelenjar limfa yang terletak di supraklavikula, poplitea dan iliaka, apabila sudah teraba maka sudah dapat dikatakan abnormal. Kelenjar epitroklear batasan abnormalnya adalah $0,5 \mathrm{~cm}$ sedangkan untuk kelenjar inguinal adalah $1,5 \mathrm{~cm}$ (Mohseni et al, 2014). Limfadenopati dapat disebabkan oleh berbagai kondisi mulai dari keganasan, infeksi, autoimun, dan iatrogenik. Limfadenopati pada usia anak dan dewasa yang ukurannya tidak bertambah besar dalam kurun waktu kurang dari dua minggu atau lebih dari 12 bulan tidak bersifat neoplastik. Terkecuali untuk kasus limfoma Hodgkin derajat rendah dan nonHodgkin indolen, namun kedua neoplasma ini memiliki ciri khas gejala sistemik (Bazemore \& Smucker 2002; Gaddey \& Riegel, 2016).

Insidensi metastasis ke kelenjar limfa leher bervariasi mulai dari sekitar $1 \%$ untuk karsinoma glotis hingga mencapai lebih dari 75\% untuk karsinoma nasofaring. Jumlah kelenjar limfa yang diinfiltrasi oleh sel ganas memiliki dampak dalam memprediksi tingkat bertahan hidup pasien. Metastasis kelenjar limfa leher memegang peranan yang esensial dalam penatalaksanaan pasien yang mengalami kanker regio kepala dan leher.

Insidensi limfadenopati di Belanda pada populasi umum mencapai 0,6\%. Dari 2.556 pasien limfadenopati yang mereka teliti, terdapat sekitar $1,1 \%$ pasien yang mengalami keganasan. Rendahnya prevalensi keganasan ini didukung oleh dua penelitian lain yang menyebutkan masingmasing bahwa terdapat tiga dari 238 pasien limfadenopati yang ternyata mengalami keganasan. Prevalensi keganasan dari semua kasus limfadenopati justru kurang dari 1\%. Di Asia, tuberkulosis 
paru (TB) justru menjadi penyebab utama limfadenopati pada pasien dewasa dan anak. Selain TB, penyebab utama limfadenopati lainnya adalah infeksi mononucleosis (Mohseni et al. 2014).

Prevalensi keganasan pada limfadenopati berbeda pada sampel yang diambil dari rumah sakit rujukan yang memiliki fasilitas biopsy, menunjukkan insidensi keganasan pada limfadenopati mencapai 40-60\%. Namun banyak yang meragukan angka ini karena pada rumah sakit rujukan yang memiliki fasilitas biopsi, mereka tidak memperhitungkan populasi pasien limfadenopati lainnya yang tidak pernah menjalani biopsi. Padahal ada sekitar 90\% pasien limfadenopati tidak pernah menjalani biopsi karena mayoritas dari mereka ditangani di pelayanan primer.

Pasien limfadenopati yang melakukan kunjungan di layanan primer diketahui bahwa pasien yang berusia 40 tahun atau lebih tua yang mengalami limfadenopati, memiliki risiko keganasan mencapai $4 \%$, sedangkan risiko untuk pasien limfadenopati yang berusia kurang dari 40 tahun mencapai 0,4\% (Yang, 2016).

Computed tomography (CT), Utrasononografi (USG), magnetic resonance imaging (MRI), dan positron emission tomography (PET) secara umum dianggap lebih superior jika dibandingkan dengan palpasi. Teknik pemeriksaan ini dapat mendeteksi hingga dua pertiga populasi pasien yang ditemukan negatif palsu pada pemeriksaan palpasi. Namun American College Radiology merekomendasikan penggunaan USG sebagai pemeriksaan awal untuk limfadenopati leher pada pasien anak sedangkan CT scan untuk pasien yang berusia di atas 14 tahun (Gaddey \& Riegel, 2016).

Deteksi dan evaluasi limfadenopati leher merupakan komponen penting dari suatu proses diagnostik dan terapi. CT scan dapat digunakan sebagai alat diagnostik untuk mendeteksi dan mengevaluasi limfadenopati leher dengan menilai gambarannya, sehingga dapat dibedakan antara yang jinak dan ganas. Tujuan penelitian ini untuk mengetahui kesesuaian gambaran CT Scan leher dibandingkan hasil BAJAH dalam membedakan limfadenopati leher yang jinak dan ganas. Dikarenakan pentingnya membandingkan lesi ganas pada CT Scan dan BAJAH untuk mengkarakterisasi gambaran radiologi lesi ganas tersebut

\section{METODE PENELITIAN}

Penelitian ini merupakan jenis penelitian observasional analitik dengan pendekatan cross sectional. Data diambil dari hasil rekam medik pasien limfadenopati yang dilakukan pemeriksaan CT Scan di bagian Radiologi dan pemeriksaan BAJAH di bagian Patologi Anatomi di RS. Dr. Wahidin Sudirohusodo dan RS Universitas Hasanuddin Makassar pada bulan Desember 2017 sampai bulan Mei 2018. Izin penelitian diperoleh dengan persetujuan Komite Etik Penelitian Biomedik pada Manusia, Fakultas Kedokteran Universitas Hasanuddin, Makassar. No 107/H4.8.4.5.31/PP36-KOMETIK/2018.

Analisis data terdiri dari analisis deskriptif dilakukan untuk melihat karakteristik distribusi jumlah dan persentase untuk jenis kelamin, umur, lokasi nodul, ukuran, bentuk, margin, nekrosis sentral, kalsifikasi, penyebaran ekstrakapsular dan hasil BAJAH. Analisis bivariat menggunakan uji Chi Square dan Analisis multivariat menggunakan uji regresi logistik ganda.

\section{HASIL DAN PEMBAHASAN}

Penelitian ini dilakukan di RS Dr. Wahidin Sudirohusodo dan RS Universitas Hasanuddin Makassar dari bulan Desember 2017 sampai Mei 2018 dan didapatkan sebanyak 61 sampel. Karakteristik sampel dapat dilihat pada Tabel I. 
Tabel I. Distribusi sampel berdasarkan demografi

\begin{tabular}{llll}
\hline & Kategori & $\mathbf{n}$ & $\mathbf{\%}$ \\
\hline \multirow{2}{*}{ Jenis Kelamin } & Perempuan & 32 & 52,5 \\
& Laki-laki & 29 & 47,5 \\
\hline & $<20$ & 5 & 8,2 \\
Umur & $20-29$ & 6 & 9,8 \\
(tahun) & $30-39$ & 18 & 29,5 \\
& $40-49$ & 14 & 23 \\
& $50-59$ & 10 & 16,4 \\
& $60-69$ & 6 & 9,8 \\
& $\geq 70$ & 2 & 3,3 \\
\hline
\end{tabular}

Keterangan, $\mathrm{n}:$ jumlah, $\%$ : persentase

Tabel I memperlihatkan distribusi sampel berdasarkan demografi. Distribusi berdasarkan jenis kelamin, limfadenopati leher lebih banyak ditemukan pada jenis kelamin perempuan sebanyak 32 (52,5\%) sampel dibandingkan laki-laki sebanyak 29 (47,5\%) sampel. Distribusi berdasarkan umur, limfadenopati leher lebih banyak ditemukan pada umur 30-39 tahun sebanyak $18(29,5 \%)$ sampel, sedangkan lebih sedikit ditemukan pada umur $\geq 70$ tahun sebanyak $2(3,3 \%)$ sampel.

Tabel II. Distribusi sampel berdasarkan lokasi nodul

\begin{tabular}{cll}
\hline Lokasi & $\mathbf{N}$ & $\mathbf{\%}$ \\
\hline Submental & 7 & 11,5 \\
Submandibular & 4 & 6,6 \\
Jugulodigastrik & 15 & 24,6 \\
Acessory spinal & 8 & 13,1 \\
Mid Jugular & 12 & 19,7 \\
Low Jugular & 12 & 19,7 \\
Trigonum & 3 & 4,9 \\
\hline Total & 61 & 100 \\
\hline
\end{tabular}

Keterangan, $\mathrm{n}$ : jumlah, \% : persentase

Tabel II memperlihatkan distribusi Sampel berdasarkan lokasi nodul, limfadenopati leher paling banyak ditemukan pada area jugulodigastrik sebanyak $15(24,6 \%)$ sampel, sedangkan paling sedikit ditemukan pada area trigonum sebanyak 3 sampel $(4,9 \%)$.

Tabel III. Distribusi karakteristik nodul berdasarkan gambaran CT Scan leher dan hasil BAJAH 


\begin{tabular}{|c|c|c|c|c|c|}
\hline \multirow{3}{*}{$\begin{array}{l}\text { Karakteristik } \\
\text { Nodul }\end{array}$} & \multirow{3}{*}{ Kategori } & \multicolumn{2}{|c|}{ Hasil BAJAH } & \multirow[t]{2}{*}{ Total } & \multirow{3}{*}{$\begin{array}{c}\text { Nilai } \\
\mathbf{p}\end{array}$} \\
\hline & & Ganas & Jinak & & \\
\hline & & $\mathrm{n}(\%)$ & $\mathrm{n}(\%)$ & $\mathrm{n}(\%)$ & \\
\hline \multirow{2}{*}{ Ukuran } & $>1,5 \mathrm{~cm}$ & $28(96,6)$ & $25(78,1)$ & $53(86,9)$ & \multirow[t]{2}{*}{0,055} \\
\hline & $\leq 1,5 \mathrm{~cm}$ & $1(3,4)$ & $7(21,9)$ & $8(13,1)$ & \\
\hline \multirow{2}{*}{ Bentuk } & Bulat/Lobulated & $28(96,6)$ & $17(53,1)$ & $45(73,8)$ & \multirow[t]{2}{*}{0,000} \\
\hline & Oval & $1(3,4)$ & $15(46,9)$ & $16(26,2)$ & \\
\hline \multirow{2}{*}{ Margin } & Irreguler & $23(79,3)$ & $5(15,6)$ & $28(45,9)$ & \multirow[t]{2}{*}{0,000} \\
\hline & Reguler & $6(20,7)$ & $27(84,4)$ & $33(54,1)$ & \\
\hline \multirow{2}{*}{ Nekrosis Sentral } & Ada & $19(65,5)$ & $4(12,5)$ & $23(37,7)$ & \multirow[t]{2}{*}{0,000} \\
\hline & Tidak Ada & $10(34,5)$ & $28(87,5)$ & $38(62,3)$ & \\
\hline \multirow{2}{*}{ Kalsifikasi } & Ada & $1(3,4)$ & $1(3,1)$ & $2(3,3)$ & \multirow[t]{2}{*}{1.000} \\
\hline & Tidak Ada & $28(96,6)$ & $31(96,9)$ & $59(96,7)$ & \\
\hline Penyebaran & Ada & $21(72,4)$ & $2(6,3)$ & $23(37,7)$ & \multirow[t]{2}{*}{0,000} \\
\hline Ekstrakapsular & Tidak Ada & $8(27,6)$ & $30(93,8)$ & $38(62,3)$ & \\
\hline
\end{tabular}

Keterangan, $\mathrm{n}$ : jumlah, \%: persentase

Tabel III memperlihatkan ukuran nodul tidak berhubungan secara bermakna dengan limfadenopati leher $(\mathrm{p}=0,055)$. Namun secara statistik, limfadenopati leher ganas lebih banyak berukuran > 1,5 cm $(96,6 \%)$ sedangkan limfadenopati leher jinak lebih banyak berukuran $\leq 1,5$ cm $(21,9 \%)$.

Hasil penelitian ini sesuai dengan penelitian Kansara et al, (2016) menyebutkan bahwa sekitar 50\% kelenjar limfa yang bersifat ganas memiliki ukuran kurang dari $5 \mathrm{~mm}$ dan sekitar 23$25 \%$ kelenjar dengan penyebaran ekstrakapsular memiliki ukuran kelenjar kurang dari $10 \mathrm{~mm}$. Bahkan terkadang hal sebaliknya justru terjadi, dimana 20\% kelenjar yang berukuran lebih dari 10 mm ternyata tidak mengandung deposit metastatik dan hanya menunjukkan hiperplasia. Hal ini untuk menekankan bahwa ukuran tidak selalu menjadi faktor yang penting dalam mengevaluasi patologi pada kelenjar limfa.

Sonmez et al 2007, menemukan bahwa jika 1,5 cm dijadikan sebagai cut-off point, maka angka negatif palsu mencapai $13 \%$, namun jika $1 \mathrm{~cm}$ digunakan sebagai cut-off point, tingkat negatif palsunya justru menjadi 7\%. Justru angka negatif palsu lebih banyak ditemukan pada cutoff point ukuran kelenjar limfa yang lebih besar. Karena variabilitas inilah maka ukuran bukanlah penanda yang dapat diandalkan untuk menentukan keganasan.

Bentuk nodul berhubungan secara bermakna dengan limfadenopati leher $(p=0,000)$. Limfadenopati leher ganas lebih sering berbentuk bulat atau lobulated $(96,6 \%)$ sedangkan limfadenopati leher jinak lebih sering berbentuk oval (46,9\%).

Hasil penelitian ini sesuai dengan Hoang et al, (2013) yang menyebutkan bahwa sebuah kelenjar limfa yang normal memiliki bentuk reniform. Proses metastasis dapat mengubah bentuk kelenjar limfa dengan cara menginfiltrasi jaringan kelenjar dan melakukan ekspansi hingga ke kapsul kelenjar. Oleh karena itu bentuk kelenjar yang bulat merupakan hal yang mencurigakan dan hal ini menandakan adanya keganasan.

Margin nodul berhubungan secara bermakna dengan limfadenopati leher $(\mathrm{p}=0,000)$. Limfadenopati leher jinak paling sering ditemukan margin reguler $(84,4 \%)$, sedangkan limfadenopati leher ganas paling sering ditemukan margin irreguler (79,3\%).

Hasil penelitian ini sesuai dengan Hoang et al, (2013), yaitu bahwa sebuah kelenjar limfa 
yang normal memiliki margin mulus yang berbatas tegas. Proses metastasis dapat mengubah bentuk kelenjar limfa dengan cara menginfiltrasi jaringan kelenjar dan melakukan ekspansi hingga ke kapsul kelenjar. Begitu penyakit semakin memberat, maka kapsul tidak lagi dapat menampung kelenjar sehingga margin kelenjar akan berbentuk ireguler dan tidak lagi berbatas tegas dan hal ini menandakan adanya keganasan. Namun kita harus berhati-hati karena kelenjar limfa yang baru saja dibiopsi atau diradiasi dapat menimbulkan inflamasi dan margin yang menyerupai gambaran keganasan.

Ada tidaknya nekrosis sentral berhubungan secara bermakna dengan limfadenopati leher $(\mathrm{p}=0,000)$. Limfadenopati leher ganas lebih sering ditemukan adanya nekrosis sentral $(65,5 \%)$ sedangkan limfadenopati leher jinak lebih sering tidak ditemukan adanya nekrosis sentral $(87,5 \%)$.

Hasil penelitian ini sesuai dengan Kansara et al (2016), yang menyebutkan bahwa metastasis selain dapat menghilangkan lemak normal pada hilus dan menimbulkan nekrosis kelenjar, gangguan morfologi lain yang dapat ditimbulkan adalah perubahan kistik dan hiperkalsifikasi. Kelenjar kistik memiliki komponen yang berasal dari kelenjar limfa namun sebagian besar telah tergantikan oleh densitas cairan dan memiliki dinding yang tipis. Lokasi tumor primer untuk gambaran morfologi kelenjar kistik adalah kanker tiroid papiler dan SCC orofaringeal. Kelenjar limfa kistik atau nekrosis dapat berukuran besar dengan tumor primer yang justru kecil atau tersembunyi. Terutama pada tumor kecil yang terletak pada dasar lidah (basis glosus) dan tonsil yang seringkali tidak bergejala dan terabaikan dalam proses pencitraan.

Ada tidaknya kalsifikasi tidak berhubungan secara bermakna dengan limfadenopati leher $(\mathrm{p}=1,000)$. Namun secara statistik, limfadenopati leher jinak lebih sering ditemukan tidak ada kalsifikasi (96,9\%), sedangkan limfadenopati leher ditemukan ada kalsifikasi dengan hasil BAJAH jinak dan ganas sama banyak yaitu $1(3,3 \%)$ sampel.

Hasil penelitian ini sesuai dengan penelitian Eisenkraft, (1999), yaitu bahwa kalsifikasi pada limfadenopati jarang ditemukan. Sebanyak 2300 sampel yang diteliti hanya 26 sampel (1\%) yang menunjukkan adanya kalsifikasi. Pada pasien dengan limfoma dan metastasis yang seharusnya ditemukan kalsifikasi justru tidak ditemukan.

Menurut Hoang et al, (2013) kelenjar limfa yang terkalsifikasi seringkali ditemukan pada karsinoma tiroid karena adanya kalsifikasi psammomatosa dengan karsinoma papilaris dan medularis. Kalsifikasi pada karsinoma papilaris memiliki tampilan berbintik. Penyebab lain dari kalsifikasi kelenjar limfa adalah adenokarsinoma musinosa, limfoma yang telah diobati, SCC kepala leher dan terkadang tuberkulosis.

Ada tidaknya penyebaran ekstrakapsular berhubungan secara bermakna dengan limfadenopati leher $(\mathrm{p}=0,000)$. Limfadenopati leher ganas lebih sering ditemukan adanya penyebaran ekstrakapsular (72,4\%) sedangkan limfadenopati leher jinak lebih jarang ada penyebaran ekstrakapsular $(93,8 \%)$.

Hasil penelitian ini sesuai dengan Chong, dan Ludwing et al, dimana mendeteksi jaringan perinodal merupakan salah satu cara untuk mengidentifikasi adanya keganasan. Jaringan perinodal yang mengalami proses keganasan biasanya memiliki gambaran berupa penyebaran ekstrakapsular (ECS) dapat ditemukan pada 60\% metastatis kelenjar limfa. Perluasan metastasis tumor di luar kelenjar limfa dapat didiagnosis jika terdapat penyangatan pada kapsul kelenjar limfa dan terdapat margin yang sulit ditentukan di sekitar kelenjar. Penyebaran ekstrakapsular diindikasikan oleh adanya kelenjar limfa yang terlihat kusut (matted) atau garis luar kelenjar limfa nampak bergarisgaris (streaky). Pencitraan tidak terlalu sensitif dan sekitar $45 \%$ dari semua kelenjar limfa yang telah terverifikasi secara histologis dengan penyebaran ekstrakapsular, tidak dapat terlihat pada CT scan. Patut dicatat bahwa sekitar 50\% kelenjar yang mengandung sel ganas berukuran kurang 
dari $5 \mathrm{~mm}$ dan $25 \%$ kelenjar yang memiliki penyebaran ekstrakapsular memiliki ukuran kurang dari $10 \mathrm{~mm}$.

Tabel IV. Model akhir uji regresi logistik ganda

\begin{tabular}{llllll}
\hline \multirow{2}{*}{ Variabel } & B & Nilai p & $\operatorname{Exp}(\mathbf{B})$ & \multicolumn{2}{c}{$\mathbf{9 5 \%}$ C.I. } \\
\cline { 5 - 6 } & & & & Lower & Upper \\
\hline Bentuk & 1,507 & 0,239 & 4,513 & 0,366 & 55,592 \\
Margin & 0,751 & 0,450 & 2,118 & 0,303 & 14,834 \\
Nekrosis & 2,593 & 0,012 & 13,376 & 1,751 & 102,175 \\
Ekstrakapsular & 3,163 & 0,008 & 23,645 & 2,277 & 245,504 \\
Constant & -3.731 & 0,003 & 0,024 & & \\
\hline
\end{tabular}

Ket $: \operatorname{Exp}(\mathrm{B})=$ odds ratio $=$ OR

Tabel IV menunjukkan nekrosis sentral dan penyebaran ekstrakapsular bersama-sama berhubungan secara bermakna dengan hasil BAJAH. Data juga menunjukkan bahwa nilai adds ratio terbesar adalah variabel penyebaran ekstrakapsular yaitu 23,645. Hal ini dapat disimpulkan bahwa variabel yang paling dominan berhubungan secara bermakna dengan limfadenopati leher ganas adalah penyebaran ekstrakapsular.

Hasil penelitian ini sesuai dengan Chong (2004), Ludwing et al, dimana mendeteksi jaringan perinodal merupakan salah satu cara untuk mengidentifikasi adanya keganasan. Jaringan perinodal yang mengalami proses keganasan biasanya memiliki gambaran berupa penyebaran ekstrakapsular (ECS) dapat ditemukan pada 60\% metastatis kelenjar limfa. Perluasan metastasis tumor di luar kelenjar limfa dapat didiagnosis jika terdapat penyangatan pada kapsul kelenjar limfa dan terdapat margin yang sulit ditentukan di sekitar kelenjar. Penyebaran ekstrakapsular diindikasikan oleh adanya kelenjar limfa yang terlihat kusut (matted) atau garis luar kelenjar limfa nampak bergaris-garis (streaky). Pencitraan tidak terlalu sensitif dan sekitar $45 \%$ dari semua kelenjar limfa yang telah terverifikasi secara histologis dengan penyebaran ekstrakapsular, tidak dapat terlihat pada CT scan.

\section{KESIMPULAN}

Terdapat kesesuaian gambaran keganasan limfadenopati leher antara hasil CT Scan berupa penyebaran ekstrakapsular, nekrosis sentral, bentuk bulat/lobulated dan margin irregular dengan hasil BAJAH. Terdapat ketidaksesuaian limfadenopati leher antara hasil CT Scan berupa kalsifikasi dan ukuran dengan hasil BAJAH. 


\section{DAFTAR PUSTAKA}

Bazemore, A.W. and Smucker, D.R. 2002. Lymphadenopathy and malignancy. American Family Physician 66(11): 2103-2110.

Chong, V. 2004. Cervical lymphadenopathy: what radiologists need to know. Cancer Imaging 4: 116-120.

Darne, S. and Radja, T. 2016. Cervical lymphadenopathy in children - a clinical approach. International Journal of Contemporary Medical Research 3(4): 1207-1210.

David, S.K, Joseph B.A., Easwarapillai B.K, \& Varma R.R. (2017). Propotion Of Malignancy In Cervical Lymphadenopathy. International Surgery Journal, 3378-3381

Eisenkraft, B.L. and Som, P.M. 1999. The spectrum of benign dan malignant etiologies of cervical node calcification. American Journal Of Roentgenology: 1433-1437

Gaddey, H.L. and Riegel, A.M. 2016. Unexplained lymphadenopathy: evaluation and differential diagnosis. American Family Physician 94(11): 896-903.

Hoang, J.K., Vanka, J., Ludwig, B.J., Glastonburry, C.M. 2013. Evaluation of cervical nodes in head and neck cancer with ct and mri: tips, traps, and a systematic approach. AJR 200: W17-W25.

Kansara, A. and Sharma, S.M. 2016. Evaluation of cervical lymphnode metastasis in oral squamous cell carcinoma: comparison between palpation, usg, ct scan \& histopathology. IOSR Journal of Dental and Medical Sciences 15(8): 49-54.

Ludwig, B. J., Wang, J., Nadgir, R. N., Saito, N., Castro-Aragon, I., \& Sakai, O. (2012). Imaging of Cervical Lymphadenopathy in Children and Young Adults. AJR, 199, 1105-1113.

Mohseni, S., Shojaiefard, A., Khorgami, Z., Alinejad, S., Ghorbani, A., Ghafouri, A. 2014. Peripheral lymphadenopathy: approach and diagnostic tools. Iran J Med Sci 39(2): 158170.

Sonmez, A., Ozturk, N., Ersoy, B., Bayramdicli, M., Celebiler, O., \& Numanoglu, A. (2007). Computed Tomography in the Management of Cervical Lymph Node Pathology. Journal of Plastic, Reconstructive and Aesthetic Surgery, 61, 61-64.

Yang, L., Luo, D., Zhao, Y., Lin, M., Guo, W., \& Zhou, C. (2016). Differentiation of Malignant Cervical Lymphadenopathy by Dual-energy CT: a Preliminary Analysis. Radiology Department, Cancer Hospital, Chinese Academy of Medical Sciences \& Peking Union Medical College. Beijing: Nature. 